\title{
Is there any relationship between vitamin D levels and the severity of diabetic peripheral neuropathy?
}

\author{
Rizaldy Taslim Pinzon, Angela Tjung, Andryawan Wahyu Pradana \\ Duta Wacana Christian University School of Medicine, Yogyakarta, Indonesia
}

\begin{abstract}
Introduction. Diabetes and its complications are the major burdens of health problems worldwide. Diabetic peripheral neuropathy is one of the major complications. Low 25-hydroxyvitamin $D$ levels have been associated with sensory neuropathy in diabetes. Vitamin D concentrations also might be correlated with the severity of the neuropathy. A recent systematic review showed that vitamin D deficiency is associated with the generation and development of DPN.

Aim. This study investigates the possible correlation between vitamin D levels and the severity of diabetic peripheral neuropathy (DPN).

Method. This study is a cross-sectional, the data were obtained from 53 subjects with diabetic peripheral neuropathy. The sample size was calculated based on an estimate of $20 \%$ prevalence of neuropathy in diabetes, allowing for an error of $10 \%$, and thereby a total of 53 patients were recruited. A standardized instrument was used to record the demographic details of the patients. The patient's clinical profile including age, gender, duration of diabetes, medication, associated microvascular complications was documented. The vitamin D levels was measured by a standardized method in Prodia Research Laboratory. The severity of neuropathy was measured with the Toronto Clinical Neuropathy Scoring System. Pearson correlation test was used to measure the correlation.

Results. The data were obtained from 53 subjects, consist of 11 males and 42 females. The mean age was $57.83 \pm 8.79$ years. The prevalence of low levels of vitamin $D$ in this study was $97.11 \%$. Gender ( $p$ value $=0.028$ ), controlled complications ( $p$ value $=0.005$ ), and hypertension ( $p$ value $=0.027$ ) have significant results. Pearson correlation test shows there were significant results between the severity of neuropathy and vitamin $D$ levels ( $p$ value $=0.000$ ).

Conclusions. The severity of diabetic peripheral neuropathy in this study is significantly associated with vitamin $D$ levels ( $p$ value $=0.000$ ).
\end{abstract}

Keywords: diabetes mellitus, vitamin D deficiency, severity of neuropathy, neuropathy, diabetic peripheral neuropathy

\section{BACKGROUND}

Diabetes and its complications are the major burden of health problem worldwide and Indonesia $(1,2)$. The data from a national health survey in Indonesia showed that the prevalence of diabetes increases $2 \%$ among $>15$ years old population (2).

Diabetic neuropathy is one of the major complications (2). The prevalence of diabetic peripheral neuropathy in newly diagnosed diabetic patients reaches about $8 \%$. The proportion increases up to $50 \%$ in patients with long-standing disease (3).
Among $15 \%$ of all diabetic patients will develop foot ulcers and nontraumatic amputation of lower limbs (4).

The pathogenesis of diabetic peripheral neuropathy is a multifactorial process and multiple hypotheses have been postulated. Previous basic research showed that abnormal expression of sodium and calcium channels, metabolic and autoimmune disorders which lead to glial cell activation contribute to the pathogenesis (5). Recent studies showed that blood vessel changes and activation of central pain mechanisms also play a significant role $(5,6)$. 
Low vitamin D levels are associated with obesity and insulin resistance (7). Recent study showed that vitamin D plays an important role in the prevention of islet cell death and may be useful to improve the survival of islet cell grafts (8). Low 25-hydroxyvitamin D levels have been associated with sensory neuropathy in diabetes (9). Vitamin D concentrations also might be correlated with the severity of the neuropathy (10).

The role of vitamin $\mathrm{D}$ in diabetic neuropathy has been studied in previous studies. A recent systematic review showed that vitamin D deficiency is associated with the generation and development of DPN in Caucasians with T2DM, and in Asian, diabetic patients with vitamin $\mathrm{D}$ deficiency are 1.22 times to suffer from DPN compared with normal vitamin D levels (11). A study showed that 25-hydroxyvitamin D levels were significantly lower in people with painful diabetic peripheral neuropathy compared with healthy volunteers and no diabetic peripheral neuropathy patients. Lower 25-hydroxyvitamin D levels also correlated with lower cold detection thresholds $(\mathrm{r}=0.39, \mathrm{p}=0.02)$ and subepidermal nerve fibre densities $(\mathrm{r}=0.42, \mathrm{p}=0.01)$ (12). The data about the vitamin D concentrations and the severity of the neuropathy in Indonesia are very limited. This study aims to investigate the possible correlation between vitamin D levels and the severity of diabetic peripheral neuropathy.

\section{MATERIALS AND METHODS}

\section{Design and subjects}

A cross-sectional study was carried out during the period from October 2019 to December 2019 on 53 subjects with diabetic peripheral neuropathy. That diagnosed with DNE (Diabetic Neuropathy Examination) and DNS (Diabetic Neuropathy Symptom). The study included all patients above the age of 18 years with type 2 Diabetes with symptoms and signs suggestive of peripheral neuropathy. Patients with neuropathy due to other causes than diabetes and those who refused informed consent were excluded from the study. The sample size was calculated based on an estimate of $20 \%$ prevalence of neuropathy in diabetes, allowing for an error of $10 \%$, and thereby a total of 53 patients were recruited. After obtaining approval from the institutional ethical committee, patients were re- cruited in the study based on the inclusion criteria. Informed consent was obtained and the patients were subjected to history and physical examination.

\section{Data collection}

The diagnosis of diabetic peripheral neuropathy based on systematic measurement by neurologist with Diabetic Neuropathy Symptom and Diabetic Neuropathy Examination tools (13). The type 2 DM patients were obtained from the outpatient neurology clinic of Bethesda Hospital Yogyakarta Indonesia. A standardized instrument was used to record the demographic details of the patients. The patient's clinical profile including age, gender, duration of diabetes, associated microvascular complications were documented. The treatment history was recorded from electronic prescribing data.

The severity of neuropathy was measured with the Toronto Clinical Neuropathy Scoring System (14). The individual patient's TCNS score was documented out of a total of 19 . The severity of neuropathy was classified based on the score as: No neuropathy ( 0 to 5), mild neuropathy (6 to 8), moderate (9 to 11), and severe diabetic neuropathy (12 to 19$)$.

The vitamin D levels was measured by a standardized method in Prodia Research Laboratory. Measurement of $25(\mathrm{OH})$ vitamin D serum levels were done by enzyme immunoassays for the quantitative measurement of total serum 25-OH Vitamin D levels. The levels $<10 \mathrm{ng} / \mathrm{ml}$ is deficiency, 10-29 $\mathrm{ng} / \mathrm{ml}$ is in-sufficiency, and $30-100 \mathrm{ng} / \mathrm{ml}$ is sufficiency.

\section{Data analysis}

Continuous variables were assessed for normality using Kolmogorov Smirnov's test. If the variables were normally distributed they were expressed as mean \pm standard deviation, otherwise median (interquartile range). Categorical variables were expressed either as percentages or proportions. A comparison of normally distributed continuous variables was done by Independent sample t-test, non-normally distributed continuous variables by the Mann-Whitney U test and Multivariate Linear Regression. Data analysis and validation were carried out by SPSS. All p values less than 0.05 were considered statistically significant. 


\section{RESULTS}

\section{Subjects characteristics}

The baseline characteristics of the study subjects are shown in Table 1. There were 53 subjects consisting of $79.2 \%$ females (42 subjects) and $20.8 \%$ males (11 subjects) with an average age of $57.83 \pm 8.79$ years. As many as $54.7 \%$ of subjects suffered from DM for $<10$ years. Subjects who had comorbid hypertension were $49.1 \%$ and $24.5 \%$ of the subjects had cardiovascular disease. For the medication, most of the subjects using anti-diabetic drugs as many as $94.3 \%$ and $37.7 \%$ use the insulin. For complications, $66 \%$ of the subjects are controlled. The prevalence of low levels of vitamin $\mathrm{d}$ in this study was $97.11 \%$. Most of the $75.5 \%$ study subjects had insufficiency and $22.6 \%$ had vitamin d deficiency, only $1.9 \%$ with normal vitamin D levels.

Table 2 presents the vitamin D levels comparison based on the characteristics of the subjects. In the normality test, the results were not significant, so we do a Non-Parametric test - Mann Whitney test was displayed in the form of mean rank and $p$ value. From the statistical test, we found 3 variables with significant results; gender ( $\mathrm{p}$ value $=$ 0.003 ), hypertension ( $\mathrm{p}$ value $=0.030$ ), controlled complications $(\mathrm{p}$ value $=0.004)$. To confirm the three variables are related as determinant factors that influence vitamin D levels, we do a multivariate linear regression test.

Table 3 presents that there were a relationship between gender, hypertension, and controlled complications with vitamin $D$ levels ( $p$ value $<0.005$ ).

TABLE 1. Characteristics and clinical features of the subjects

\begin{tabular}{|c|c|c|c|}
\hline Characteristic & & Amount $(n=53)$ & Percentage (\%) \\
\hline \multirow[t]{2}{*}{ Gender } & Male & 11 & $20.8 \%$ \\
\hline & Female & 42 & $79.2 \%$ \\
\hline Duration of DM (years) & $\begin{array}{l}-<10 \\
-10-15 \\
->15\end{array}$ & $\begin{array}{l}29 \\
12 \\
12 \\
\end{array}$ & $\begin{array}{l}54.7 \% \\
22.6 \% \\
22.6 \% \\
\end{array}$ \\
\hline Age, mean $\pm S D$ & $\begin{array}{l}57.83 \pm 8.79 \\
\text { Minimum: } 43 \\
\text { Maximum: } 82 \\
-<60 \text { years old } \\
-\geq 60 \text { years old }\end{array}$ & $\begin{array}{l}33 \\
20\end{array}$ & $\begin{array}{l}62.2 \% \\
37.8 \%\end{array}$ \\
\hline \multirow[t]{2}{*}{ Medication } & $\begin{array}{l}\text { Insulin } \\
\text { - Yes } \\
\text { - No } \\
\end{array}$ & $\begin{array}{l}20 \\
33 \\
\end{array}$ & $\begin{array}{l}37.7 \% \\
62.3 \% \\
\end{array}$ \\
\hline & $\begin{array}{l}\text { Anti-diabetic drug } \\
\text { - Yes } \\
\text { - No }\end{array}$ & $\begin{array}{c}50 \\
3 \\
\end{array}$ & $\begin{array}{c}94.3 \% \\
5.7 \% \\
\end{array}$ \\
\hline \multirow[t]{2}{*}{ Comorbidity } & $\begin{array}{l}\text { Cardiovascular } \\
\text { - Yes } \\
\text { - No } \\
\end{array}$ & $\begin{array}{l}13 \\
40\end{array}$ & $\begin{array}{l}24.5 \% \\
75.5 \%\end{array}$ \\
\hline & $\begin{array}{l}\text { Hypertension } \\
\text { - Yes } \\
\text { - No } \\
\end{array}$ & $\begin{array}{l}26 \\
27 \\
\end{array}$ & $\begin{array}{l}49.1 \% \\
50.9 \% \\
\end{array}$ \\
\hline Complications & $\begin{array}{l}\text { Controlled } \\
\text { - Yes } \\
\text { - No } \\
\end{array}$ & $\begin{array}{l}35 \\
18 \\
\end{array}$ & $\begin{array}{l}66.0 \% \\
34.0 \% \\
\end{array}$ \\
\hline $\begin{array}{l}\text { Neuropathy Toronto } \\
\text { Score, mean } \pm \text { SD }\end{array}$ & $\begin{array}{l}11.38 \pm 2.91 \\
\text { Minimum: } 8 \\
\text { Maximum: } 18 \\
\text { No neuropathy (0-5) } \\
\text { Mild neuropathy }(6-8) \\
\text { Moderate }(9-11) \\
\text { Severe }(12-19)\end{array}$ & $\begin{array}{c}0 \\
11 \\
19 \\
23 \\
\end{array}$ & $\begin{array}{c}0 \% \\
20.8 \% \\
35.8 \% \\
43.4 \% \\
\end{array}$ \\
\hline Vitamin D levels (ng/ml) & $\begin{array}{l}15.57 \pm 6.99 \\
\text { Minimum: } 5 \\
\text { Maximum: } 36 \\
\text { Deficiency }<10 \\
\text { Insufficiency } 10-29 \\
\text { Sufficiency } 30-100\end{array}$ & $\begin{array}{c}12 \\
40 \\
1\end{array}$ & $\begin{array}{c}22.6 \% \\
75.5 \% \\
1.9 \%\end{array}$ \\
\hline
\end{tabular}


TABLE 2. The vitamin D levels comparison based on the characteristic of the subjects

\begin{tabular}{|c|c|c|}
\hline Variable & $\begin{array}{l}\text { Mean rank vitamin } \\
\text { D levels } \\
\end{array}$ & $p$ value \\
\hline $\begin{array}{l}\text { - Male } \\
\text { - Female }\end{array}$ & \begin{tabular}{|l}
39.32 \\
23.77
\end{tabular} & $0.003^{*}$ \\
\hline $\begin{array}{l}\text { Duration of DM (years) } \\
-<10 \\
-10-15 \\
->15\end{array}$ & $\begin{array}{l}28.03 \\
32.21 \\
19.29 \\
\end{array}$ & 0.105 \\
\hline $\begin{array}{l}\text { Age } \\
-<60 \text { years old } \\
-\geq 60 \text { years old } \\
\end{array}$ & $\begin{array}{l}25.44 \\
29.58 \\
\end{array}$ & 0.344 \\
\hline $\begin{array}{l}\text { Insulin } \\
\text { - Yes } \\
\text { - No }\end{array}$ & \begin{tabular}{|l|}
27.43 \\
26.74 \\
\end{tabular} & 0.876 \\
\hline $\begin{array}{l}\text { Anti-diabetic drug } \\
\text { - Yes } \\
\text { - No }\end{array}$ & $\begin{array}{l}27.18 \\
24.00\end{array}$ & 0.729 \\
\hline $\begin{array}{l}\text { Cardiovascular disease } \\
\text { - Yes } \\
\text { - No } \\
\end{array}$ & $\begin{array}{l}27.73 \\
26.76 \\
\end{array}$ & 0.844 \\
\hline $\begin{array}{l}\text { Hypertension } \\
\text { - Yes } \\
\text { - No } \\
\end{array}$ & $\begin{array}{l}31.67 \\
22.50 \\
\end{array}$ & $0.030 *$ \\
\hline $\begin{array}{l}\text { Controlled complications } \\
\text { - Yes } \\
\text { - No }\end{array}$ & $\begin{array}{l}31.43 \\
18.39\end{array}$ & $0.004 *$ \\
\hline
\end{tabular}

*significance when $p$ value $<0.05$

TABLE 3. Multivariate linear regression model for vitamin $D$ levels

\begin{tabular}{|l|l|l|l|}
\hline $\begin{array}{l}\text { Independent } \\
\text { Variables }\end{array}$ & $\mathbf{p}$ value & $\begin{array}{l}\text { Standardized } \\
\boldsymbol{\beta}\end{array}$ & $\begin{array}{l}\mathbf{9 5 . 0 \%} \text { Confidence } \\
\text { interval }\end{array}$ \\
\hline Gender & $\mathbf{0 . 0 2 8 *}$ & -0.273 & -8.812 to -0.537 \\
\hline Hypertension & $\mathbf{0 . 0 2 7}$ & 0.270 & 0.442 to 7.057 \\
\hline $\begin{array}{l}\text { Controlled } \\
\text { Complications }\end{array}$ & $\mathbf{0 . 0 0 5 *}$ & 0.355 & 1.688 to 8.695 \\
\hline
\end{tabular}

*significance when $p$ value $<0.05$

Table 4 presents the vitamin d levels based on the severity of neuropathy. The severity of neuropathy was measured by the Toronto Clinical Neuropathy Scoring System. The severity of neuropathy was classified based on the score as: No neuropathy (0 to 5), mild neuropathy (6 to 8), moderate (9 to 11 ), and severe diabetic neuropathy (12 to 19$)$. From 53 research subjects, $20.8 \%$ of subjects had mild degrees, $35.8 \%$ of subjects had moderate degrees, $43.4 \%$ of subjects had severe degrees.

TABLE 4. The vitamin $D$ levels based on the severity of neuropathy

\begin{tabular}{|l|l|l|l|}
\hline \multirow{2}{*}{$\begin{array}{l}\text { Vitamin D } \\
\text { levels }\end{array}$} & \multicolumn{3}{|l|}{ Severity of neuropathy } \\
\cline { 2 - 4 } & Mild (6-8) & Moderate (9-11) & Severe (12-19) \\
\hline Total & 11 & 19 & 23 \\
\hline Percentage & $20.8 \%$ & $35.8 \%$ & $43.4 \%$ \\
\hline Mean rank & 33.64 & 29.00 & 22.17 \\
\hline
\end{tabular}

This study showed the Pearson correlation value (Table 5) obtained -0.489 , which shows there was a relationship in a moderate degree. A negative result (- 0.489) indicates an inverse relationship direction. The lower of vitamin D levels, the greater the neuropathy score will be obtained. The significance in this study ( $\mathrm{p}$ value $=0.000$ ) is smaller than $0.05(\mathrm{p}$ value $<0.05)$ which shows there were a relationship between vitamin D levels and the severity of neuropathy.

TABLE 5. Relationship between vitamin D levels and severity of neuropathy

\begin{tabular}{|c|c|}
\hline \multicolumn{2}{|l|}{ Vitamin D levels } \\
\hline \multirow{3}{*}{$\begin{array}{l}\text { Severity of Neuropathy - } \\
\text { Toronto Scoring }\end{array}$} & $\begin{array}{l}\text { Pearson correlation coefficient }= \\
-\mathbf{0 . 4 8 9}\end{array}$ \\
\hline & Significance $=\mathbf{0 . 0 0 0}$ \\
\hline & $N=53$ \\
\hline
\end{tabular}

* Correlation test - Pearson

\section{DISCUSSION}

Diabetes is a major lifestyle disease and has become a global burden. The prevalence of diabetes is increasing rapidly especially in developing countries (15). Indonesia is one of the developing countries which occupies the 6th position in the world with the highest DM prevalence. Based on the International Diabetes Federation in 2017, there were 10.3 million people with DM in Indonesia. One of the most common complications for DM patients is diabetic peripheral neuropathy (DPN). Neuropathy is a neurological disorder that affects the nerves of distal limbs (16). Previous study confirmed lower vitamin D was an independent factor of DPN (17).

The current study included a total of 53 patients with type 2 diabetes mellitus with an average age of 57.83 years and most of them are females $(79.2 \%)$. Especially the study found that gender $(p=0.028)$, hypertension $(p=0.027)$, and controlled complications ( $p$ value $=0.005)$ were significantly associated to inadequate vitamin D. In addition, there was a significant negative correlation between vitamin D levels and severity neuropathy.

The data showed that only one study subjects (1.9\%) has sufficient vitamin D levels. The proportion of subjects with deficiency is significant $12 / 53$ (22.6\%). Most of the study subjects have insufficient vitamin D levels (75.5\%). This result is consistent with some previous studies. The study from 
Bayani et al. from 120 diabetic patients showed that vitamin D levels was deficient present in 77 (64.2\%) patients, insufficient in $30(25 \%)$ patients, and sufficient in $13(10.3 \%)$ patients (18). A large epidemiological study showed that the overall prevalence of patients with low vitamin D levels (vitamin D deficiency and insufficiency) was 1,257 (83.7\%); 1,231 (82\%) were newly diagnosed cases. Out of 1,257 (83.7\%) patients with low vitamin D levels, $60.9 \%$ of patients had vitamin D deficiency and $22.9 \%$ patients had vitamin D insufficiency (19).

Inadequate vitamin $\mathrm{D}$ is prevalent in patients with type 2 diabetes mellitus and its related peripheral neuropathy. Previous studies showed that $25-\mathrm{OH}$ vitamin D inadequate was associated with decreased parasympathetic function, with stronger associations in younger type 2 diabetes patients (20). Another study in patients with type 2 diabetes also confirms there was a relationship between vitamin $\mathrm{D}$ deficiency and neuropathy incidence as well as the severity of symptoms caused by neuropathy (21).

This study showed the patients with severe neuropathy significantly correlated with low vitamin D levels $(\mathrm{p}$ value $=0.000$ ). Some previous studies showed a similar result. The study from 60 patients with diabetes (thirty with neuropathy and thirty without neuropathy). Vitamin D levels was significantly decreased in diabetic patients and also in those with neuropathy when compared to those without neuropathy $(\mathrm{p}<0.05)$. Vitamin D levels was significantly reduced with increasing severity of neuropathy $(p=0.001)(22)$. Another study done by Ahmadieh et al. confirmed that lower vitamin D was an independent factor of DPN and reported that the prevalence of diabetic neuropathy increases with a decrease in $25(\mathrm{OH})$ vitamin D levels. The percentage of neuropathy increased in patients with 25(OH)vitamin D levels below $20 \mathrm{ng} / \mathrm{ml}$ (17).

In this study, the correlation value obtained -0.489 which shows there is a relationship to a moderate degree. A negative result (-0.489) indicates an inverse relationship direction. The lower the vitamin D levels, the greater the neuropathy score will be obtained. A previous study found a significant inversely relation of vitamin with rapid nerve conduction impairment $p$ value: 0.001 (23).

The severity of neuropathy in our study was measured by the Toronto Clinical Neuropathy
Scoring System. Patients were further divided into subgroups according to neuropathy severity into the mild, moderate, and severe groups. A total of $20.8 \%$ of subjects had mild degrees, $35.8 \%$ of subjects had moderate degrees, $43.4 \%$ of subjects have severe degrees. Severity neuropathy in this study is significantly associated with vitamin D levels ( $p$ value $=0.000)$. Vitamin $\mathrm{D}$ supplementation in 51 patients with DPN in a past study, resulted in a significant improvement in neuropathic pain scores (24). After measurement with TCNSS, there was an increase in nerve conduction in previous studies in peripheral neuropathy of mild diabetes after vitamin D supplementation but does not affect moderate and severe cases (25). Improvement of neuropathy symptoms after vitamin D supplementation is explained in light of the induction of nerve growth factor synthesis by vitamin $\mathrm{D}$ derivatives as shown in vitro in fibroblasts and astrocytes and in vivo in rat brain (26). In addition, the pain threshold of painful diabetic neuropathy in patients with hypovitaminosis D has been reported to decrease and improve when vitamin D deficiency is corrected (27).

Several clinical studies had shown a significant relationship between vitamin D deficiency and clinical severity manifestations of diabetic neuropathy (sensory, neurological deficit) (28). There was emerging evidence that vitamin D was a neurotrophic substance, but its role in diabetic neuropathic pain need more further studies (29). Some researchers hypothesized that vitamin D deficiency may potentiate diabetic nerve damage and may impair nociceptor function, resulting in pain at a threshold of serum $25(\mathrm{OH})$ vitamin $\mathrm{D}$ higher than that in the non-diabetic population (30).

Patients with diabetic peripheral neuropathy (DPN) in this study mostly had vitamin D deficiency. They feel neuropathic pain due to pain and thermal perception are mediated by small sensory fibers. Vitamin D deficiency may have a role in the pathogenesis of small-fiber neuropathy particularly affecting nociceptors, contributing to the development of pain in DPN (12). The past study demonstrated in experimental animals, vitamin D deficiency shown to be related to low neurotrophin levels (especially in nerve growth factors) and homeostasis of damaged calcium neurons (31).

Vitamin D has an important role in promoting nerve growth factor (NGF) secretion. Vitamin D 
deficiency will interfere with the process of NGF secretion and may lead to the development of clinical diabetic small fiber neuropathy because NGF is a target-derived protein that regulates the phenotype and sensitivity of nociceptor fibers (12).

In this study, hypertension was significantly related to vitamin d levels. Clinical studies show there was an inverse relationship, a dose-response relationship between plasma 1,25(OH)2D3 concentration, and blood pressure (32). Metabolites vitamin $\mathrm{D}$ is known to reduce endothelial dependency on vascular muscle contraction and vascular tone in hypertensive rats by influencing the entry of calcium in endothelial cells (33). Vitamin D3 supplementation is confirmed to reduce blood pressure in patients with essential hypertension (34).

The next important question is: "Should we give add on vitamin D treatment in patients with painful diabetic neuropathy?". A quasi-experimental trial sixty type 2 DM subjects (30-65 years old) with painful diabetic neuropathy was performed. Patients received weekly 50,000 IU of vitamin D3 for 12 weeks orally. Among 60 T2DM patients, 58 completed the study. At the end of the study, HbA1c, vitamin D, MNSI (both questionnaire and physical examination) improved that is statistically significant ( $\mathrm{p}$ value $<0.001)$. Oral supplementation of vitamin D 3 (50,000 IU) once weekly for 12 weeks was associated with a significant decrease in the symptoms and signs of diabetic neuropathy (35). Lee and Chen showed that vitamin D supple-

\section{REFERENCES}

1. Boulton A, Malik R, Arezzo J, Sosenko J. Diabetic somatic neuropathies (technical review). Diabetes Care. 2004;27:1458-86.

2. Ministry of Health Indonesia. Indonesian Health Survey. Indonesia. 2018.

3. Dang $\mathrm{C}$, Boulton $\mathrm{A}$. Changing perspectives in diabetic foot ulcer management. Int J Low Extrem Wounds Mar. 2003;2(1):4-12.

4. Tesfaye S, Boulton A, Dyck P, Freeman R, Horowitz M, Kempler P, et al. Diabetic neuropathies: update on definitions, diagnostic criteria, estimation of severity, and treatments. Diabetes Care. 2010; 33:2285-93.

5. Tahrani A, Ball A, Shepherd L, Rahim A, Jones A, Bates A. The prevalence of vitamin $D$ abnormalities in South Asians with type 2 diabetes mellitus in the UK. Int J Clin Pract. 2010;64:351-5.

6. Usluogullari C, Balkan F, Caner S, Ucler R, Kaya C, Ersoy R, et al. The relationship between microvascular complications and vitamin $D$ deficiency in type 2 diabetes mellitus. BMC Endocr Disord. 2015;15:33.

7. Lee J, Oh S, Ha W, Kwon H, Sohn T, Son H, Cha B. Serum 25-hydroxyvitamin $\mathrm{D}$ concentration and arterial stiffness among type 2 diabetes. Diabetes Res Clin Pract. 2012;95(1):42-7.

8. Suzuki A, Kotake M, Ono Y, Kato T, Oda N, Hayakawa N, Hashimoto $\mathrm{S}$, Itoh M. Hypovitaminosis D in type 2 diabetes mellitus: association mentation over 3 months improved neuropathic symptoms by $50 \%$ in diabetic patients with vitamin $\mathrm{D}$ deficiency at baseline (24).

The past study evaluated that intramuscular injection, 600,000 IU of vitamin D, could improve and reduce the pain of patients with DPN (27). Short-term oral administration of vitamin D significantly increases the concentration of $25(\mathrm{OH}) \mathrm{D}$ and can improve symptoms of peripheral neuropathy (36). Other studies confirm that taking vitamin $\mathrm{D}$ can increase serum calcium, reduce free fat circulating acid concentrations, increase insulin secretion, and also increase glucose tolerance in DPN patients (37).

The study has some limitations. It was a hospital-based study and hence the results may not be generalized to the population on a community basis. The authors could not find sufficient subjects with normal vitamin D status. We also do not compare the vitamin D levels in patients without neuropathy. Further studies and clinical trials are warranted.

\section{CONCLUSIONS}

In this study, most of the study subjects $(75.5 \%)$ have insufficient vitamin D levels. The severity of diabetic peripheral neuropathy in this study is significantly associated with vitamin $D$ levels ( $p$ value $=0.000)$. Most of the study subjects (43.4\%) have severe degrees.

Conflict of interest: none declared Financial support: none declared

with microvascular complications and type of treatment. Endocr $\mathrm{J}$. 2006;53(4):503-10.

9. Al-Timimi D, Ali A. Serum $25(\mathrm{OH}) \mathrm{D}$ in diabetes mellitus type 2 : Relation to glycaemic control. J Clin Diagn Res. 2013;7(12):2686-8.

10. Olt $S$. Relationship between vitamin $D$ and glycemic control in patients with type 2 diabetes mellitus. Int J Clin Exp Med. 2015;8(10):19180-3.

11. Qu GB, Wang LL, Tang X, Wu W, Sun YH. The association between vitamin $\mathrm{D}$ level and diabetic peripheral neuropathy in patients with type 2 diabetes mellitus: An update systematic review and metaanalysis. J Clin Transl Endocrinol. 2017;9:25-31.

12. Shillo $P$, Selvarajah $D$, Greig M, et al. Reduced vitamin $D$ levels in painful diabetic peripheral neuropathy. Diabet Med. 2019,36(1):4451.

13. Maje JWG, Bosma E, Lefrandt JD, et al. Clinical Diagnosis of Diabetic Polyneuropathy With the Diabetic Neuropathy Symptom and Diabetic Neuropathy Examination Scores. Diabetes Care. 2003;26(3):697-701.

14. Bril V, Perkins B. Validation of the Toronto clinical scoring system for diabetic polyneuropathy. Diabetes Care. 2002;25(11):2048-52. 
15. Zhang B, Zhao W, Tu J, et al. The relationship between serum 25-hydroxyvitamin $D$ concentration and type 2 diabetic peripheral neuropathy: A systematic review and a meta-analysis. Medicine (Baltimore). 2019;98(48):e18118.

16. Federation, ID. IDF Diabetes Atlas 8th Edition 2017. In International Diabetes Federation. Brussels, Belgium, 2017.

17. Ahmadieh $\mathrm{H}, \mathrm{Azar} \mathrm{ST}$, Lakkis $\mathrm{N}$, et al. Hypovitaminosis d in patients with type 2 diabetes mellitus: A relation to disease control and complications. ISRN Endocrinol. 2013;2013:641098.

18. Bayani MA, Akbari R, Banasaz B, Saeedi F. Status of vitamin-D in diabetic patients. Caspian J Intern Med. 2014;5(1):40-42.

19. Talwalkar PG, Deshmukh V, Deepak MC, et al. Prevalence and clinico-epidemiology of vitamin $D$ deficiency in patients with type 2 diabetes mellitus and hypertension - a Pan-India study. Endocrine Abstracts 2018;56;P218.

20. Maser RE, Lenhard MJ, Poglig RT. Vitamin D insufficiency is associated with reduced parasympathetic nerve fiber function in type 2 diabetes. Endocr Pract. 2015;21:174-81.

21. Putz Z, Martos T, Németh N, Körei AE, Vági OE, Kempler MS, et al. Is there an association between diabetic neuropathy and low vitamin D levels? Curr Diab Rep. 2014;14:537.

22. Alla Dalia IW, Abdelmula MA, Zeinab AE, et al. Association of vitamin $D$ with diabetic neuropathy among Sudanese patients with type 2 diabetes mellitus. Niger J Basic Clin Sci. 2019;16:79-82.

23. Alamdari A, Mozafari R, Tafakhori A, et al. An inverse association between serum vitamin $D$ levels with the presence and severity of impaired nerve conduction velocity and large fiber peripheral neuropathy in diabetic subjects. Neurol Sci. 2015;36:1121-6.

24. Lee $P, C h e n R$. Vitamin $D$ as an analgesic for patients with type 2 diabetes and neuropathic pain. Arch Intern Med. 2008;1680:771-2.

25. Ghadiri-Anari A, Mozafari Z, Gholami S, et al. Dose vitamin D supplementations improve peripheral diabetic neuropathy? A before-after clinical trial. Diabetes \& Metabolic Syndrome. 2019;13(1):890-893

26. Pfeifer M, Begerow B, Minne HW, Abrams C, Nachtigall D, Hansen C. Effects of a short-term vitamin $\mathrm{D}$ and calcium supplementation on body sway and secondary hyperparathyroidism in elderly women. J Bone Miner Res. 2001;15:1113-8.

27. Bell DS. Reversal of the symptoms of diabetic neuropathy through correction of vitamin $\mathrm{D}$ deficiency in a type 1 diabetic patient. Case Rep Endocrinol. 2012;2012:165056.
28. Soderstrom LH, Johnson SP, Diaz VA, Mainous AG 3rd. Association betweenvitamin $D$ and diabetic neuropathy in a nationally representative sample: Results from 2001-2004 NHANES. Diabet Med. 2012;29:50-5.

29. Shehab D, Al-Jarallah K, Mojiminiyi O, Al Mohamedy H, Abdella N. Does vitamin $D$ deficiency play a role in peripheral neuropathy in type 2 diabetes? Diabet Med. 2012;29:43-9.

30. Bilir B, Tulubas F, Bilir B, Atile N, Kara S, Yildirim T, et al. The association of vitamin $\mathrm{D}$ with inflammatory cytokines in diabetic peripheral neuropathy. J Phys Ther Sci. 2016;28:2159-63.

31. Ghadiri-Anari A, Mozafari Z, Gholami S, et al. Dose vitamin D supplementations improve peripheral diabetic neuropathy? A before-after clinical trial. Diabetes Metab Syndr. 2019;13(1):890-893.

32. Nigwekar SU, Thadhani R. Vitamin D receptor activation: Cardiovascular and renal implications. Kidney International Supplements. 2013;3:427-430.

33. Wong MSK, Delansorne R, Man RYK, Vanhoutte PM. Vitamin D derivatives acutely reduce endothelium-dependent contractions in the aorta of the spontaneouslyhypertensive rat. The American Journal of Physiology - Heart and Circulatory Physiology. 2008;295:289-296.

34. Pfeifer M, Begerow B, Minne HW, Nachtigall D, Hansen C. Effects of a short-term vitamin $\mathrm{D}$ and calcium supplementation on blood pressure and parathyroid hormonelevels in elderly women. Journal of Clinical Endocrinology and Metabolism. 2001;86:1633-1637.

35. Basit A, Basit KA, Fawwad A, et al. Vitamin D for the treatment of painful diabetic neuropathy. BMJ Open Diabetes Res Care. 2016:4:e000148.

36. Shehab D, Al-Jarallah K, Abdella N, et al. Prospective evaluation of the effect of short-term oral vitamin $D$ supplementation on peripheral neuropathy in type 2 diabetes mellitus. Med Princ Pract. 2015;24:250-6.

37. Alvarez JA, Ashraf A. Role of vitamin D in insulin secretion and insulin sensitivity for glucose homeostasis. Int J Endocrinol. 2010;2010:351385. 